\title{
A MOLECULAR PHYLOGENY OF THE DOVE GENERA STREPTOPELIA AND COLUMBA
}

\author{
Kevin P. Johnson,,$^{1,3,5}$ Selvino de Kort, ${ }^{2}$ Karen Dinwoodey, ${ }^{3}$ A. C. Mateman, ${ }^{4}$ \\ Carel ten Cate, ${ }^{2}$ C. M. Lessells, ${ }^{4}$ and Dale H. Clayton ${ }^{3}$ \\ ${ }^{1}$ Illinois Natural History Survey, Champaign, Illinois 61820, USA; \\ 2Institute of Evolutionary and Ecological Sciences, Leiden University, Leiden, The Netherlands; \\ ${ }^{3}$ Department of Biology, University of Utah, Salt Lake City, Utah 84112, USA; and \\ ${ }^{4}$ Netherlands Institute of Ecology, Heteren, The Netherlands
}

\begin{abstract}
Evolutionary history of the dove genus Streptopelia has not been examined with rigorous phylogenetic methods. We present a study of phylogenetic relationships of Streptopelia based on over 3,600 base pairs of nuclear and mitochondrial gene sequences. To test for monophyly of Streptopelia, we used several other columbiform taxa, including Colum$b a$ (Old and New World), Macropygia, Reinwardtoena, and the enigmatic Pink Pigeon (Nesoenas mayeri). On the basis of our analyses, Streptopelia (as currently defined) is not monophyletic; Nesoenas mayeri is the sister species to S. picturata, resulting in paraphyly of Streptopelia. Three main clades of Streptopelia are identified: (1) S. chinensis plus S. senegalensis, (2) S. picturata plus Nesoenas mayeri, and (3) all other species of Streptopelia. It is unclear whether those clades form a monophyletic group to the exclusion of Old World Columba, but several analyses produce that result. Species of Old World Columba are closely related to Streptopelia, with species of New World Columba clustering outside that group. Taxonomic changes suggested by our results include merging Nesoenas with Streptopelia and changing the generic name for New World Columba species to Patagioenas. Vocal similarities between S. picturata and N. mayeri are striking, given the general diversity of vocalizations in other species. Received 20 September 2000, accepted 27 March 2001.
\end{abstract}

SPECIES OF DOVES in the genus Streptopelia are important model systems for studies of physiology (Walker et al. 1983, Janik and Buntin 1985, Cheng 1986, Ramos and Silver 1992, ten Cate et al. 1993, Lea et al. 1995, Georgiou et al. 1995) and behavior (Lade and Thorpe 1964, Zenone et al. 1979, Cheng et al. 1981, Cheng 1992, Slabbekoorn and ten Cate 1998, Slabbekoorn et al. 1999). The 16 species of Streptopelia historically had an African and Eurasian distribution, but some species have been introduced to the New World and Australia. Several species of Streptopelia seem highly adaptable to human-altered environments and have expanded their ranges considerably (e.g. S. decaocto; Bijlsma 1988, Hengeveld and van den Bosch 1991, Hengeveld 1993, Kasparek 1996). Other species have remarkably localized distributions (e.g. S. hypopyrrha). An understanding of historical relationships would provide an important context for work on physiology, behavior, and biogeography of this genus.

Even though species of Streptopelia have been well studied in many respects, phylogenetic re-

${ }^{5}$ E-mail: kjohnson@inhs.uiuc.edu lationships within the genus are uncertain. Nowak (1975) examined morphological characteristics within Streptopelia and produced a classification that grouped species into several subgenera. However, he did not produce an explicit phylogenetic tree. Goodwin (1983) depicts a tree of "presumed relationships" among species of Streptopelia, and that tree differs from Nowak's classification, but Goodwin's tree is not based on a rigorous phylogenetic analysis. Johnson and Clayton (2000a) showed that species of Old World Columba form the sister group to Streptopelia, with species of New World Columba being more distantly related to both groups. However, the authors included only single representatives of Streptopelia and Old World Columba in their study. The goal of the present study is to assess monophyly of the genus Streptopelia and identify relationships within the genus. We also use this study to test Nowak's (1975) classification and Goodwin's (1983) proposed relationships of species within the genus. We include several representatives of New and Old World Columba, as well as the endangered, enigmatic Pink Pigeon (Nesoenas mayeri) of Mauritius. We also include represen- 
tatives of Macropygia and Reinwardtoena, which together with Columba and Streptopelia form a distinct clade within Columbiformes (Johnson and Clayton 2000a). The entire phylogenetic analysis is rooted on Geotrygon, Leptotila, and Zenaida, which together consitute the sister group to the Columba/Streptopelia/Macropygia clade (Johnson and Clayton 2000a).

For our current study, we use sequences of both mitochondrial and nuclear genes to construct a phylogeny for Streptopelia, Columba, and related taxa. We compare relative usefulness of nuclear and mitochondrial genes for phylogenetic resolution at that level. Using the phylogeny we recommend some changes in taxonomic classification, and compare phylogeny to vocal similarities and diversity in Streptopelia.

\section{Methods}

Sequencing.-We obtained samples of muscle tissues, feathers, or blood from representatives of 14 of the 16 described species of Streptopelia (Table 1). We also sampled members of New and Old World Columba, Macropygia, Reinwardtoena, Nesoenas, Geotrygon, Leptotila, and Zenaida. We extracted DNA from those samples using a Qiagen Tissue Kit (Valencia, California) with the manufacturer's protocols. For feather samples ( $\sim 2 \mathrm{~mm}$ of the tip of the shaft) we also added $30 \mu \mathrm{L}$ of $10 \%$ DTT to the digestion buffer Using PCR we amplified portions of three mitochondrial genes: cytochrome- $b$ (cyt $b$ ), cytochrome oxidase I (COI), and NADH dehydrogenase subunit 2 (ND2). We also amplified the nuclear gene $\beta$-fibrinogen intron 7 (FIB7). Table 2 lists primers used for those reactions. Protocols for reactions follow Johnson and Clayton (2000a).

Direct sequencing of PCR products and determination of sequences was performed as described by Johnson and Clayton (2000a). We aligned sequences across species using Sequencher (GeneCodes, Madison, Wisconsin). The three mitochondrial genes totaled 2,520 bp and the nuclear intron included 1,150 aligned base pairs (GenBank accession numbers in Table 1). In the case of mitochondrial protein coding genes, alignment was straightforward. We noted several insertion-deletion (indel) events in the nuclear intron, but for those taxa, divergences were so low that manual alignment was straightforward. Gaps were treated as missing data in phylogenetic analyses. For Streptopelia tranquebarica and S. bitorquata, only partial FIB7 sequences were available because of amplification failures. Thus, we repeated analyses involving the nuclear intron both with and without those species.

For each species, we included single representatives for all sequences. However, to assess the level of individual variation within each species, we sequenced (when available) multiple individuals for the COI gene (see Table 3 for list of those multiple individuals and GenBank accession numbers). Mitochondrial genes tend to evolve at similar rates at low levels of sequence divergence in birds (Johnson and Sorenson 1998, Johnson and Lanyon 1999) and more specifically for cyt $b, \mathrm{ND} 2$, and COI in Columbiformes (Johnson and Clayton 2000b). Mitochondrial divergences are also highly correlated with divergences in FIB7 in Columbiformes (Johnson and Clayton 2000a, b). Thus, within-species variation in COI sequences is likely to be representative of other mitochondrial and nuclear genes. In general, individuals of the same species differed only slightly, if at all, in those COI sequences (see below), so single exemplar individuals are reasonable for the multigene data set.

Where possible, we used tissue or feather samples to avoid risk of nuclear copies of mitochondrial genes (Sorenson and Quinn 1998). In cases where blood samples were used, we verified sequences for COI using multiple individuals. We also checked chromatograms for signs of double peaks, as well as checking for indels and stop codons. By sequencing several mitochondrial genes, we were also able to test for any incongruence in phylogenies resulting from those gene regions, which would likely occur if some of the sequences represented nuclear copies. We found no evidence of nuclear copies in our sequences.

Phylogenetic analysis. - Relative rates of substitution can be examined by plotting pairwise sequence divergences for various substitution types and genes. For the nuclear gene (FIB7), we estimated the "native" transition:transversion ratio by plotting pairwise transition differences against pairwise transversion differences. Slope of the linear portion of that curve estimates the transition:transversion ratio (Sturmbauer and Meyer 1992). We do not fit regressions through those points because they are nonindependent, rather we use slopes as a rough indicator of relative rates. For mitochondrial genes, we plotted transition difference at third positions against transversions at third positions to estimate that ratio. To estimate relative rates of mitochondrial versus nuclear substitution, we plotted pairwise divergences for mitochondrial genes against those for FIB7. We also plotted pairwise divergences for individual mitochondrial genes against each other and against FIB7 to determine which genes are more subject to multiple substitution.

PAUP* (Swofford 2000) was used for all phylogenetic analyses. We used the partition homogeneity test (Farris et al. 1994, 1995; Swofford 2000) to examine whether the gene regions could be considered samples of the same underlying phylogeny, or whether there was evidence for different phylogenetic signal between gene regions. Even though that 
TABLE 1. Samples sequenced for all genes.

\begin{tabular}{|c|c|c|c|c|c|c|c|}
\hline \multirow[b]{2}{*}{ Species } & \multirow[b]{2}{*}{ Locality } & \multirow[b]{2}{*}{ Sample number } & \multirow[b]{2}{*}{ Tissue type } & \multicolumn{4}{|c|}{ GenBank accession numbers } \\
\hline & & & & Cyt $b$ & ND2 & $\mathrm{COI}$ & FIB7 \\
\hline Streptopelia decaocto & Netherlands & SDK 4 & Muscle & AF353398 & AF353418 & AF353469 & AF353449 \\
\hline Streptopelia roseogrisea & Cameroon & SDK 1 & Feather & AF353399 & AF353419 & AF353470 & AF353450 \\
\hline Streptopelia decipiens & Cameroon & SDK 1 & Feather & AF353400 & AF353420 & AF353471 & AF353451 \\
\hline Streptopelia semitorquata & South Africa & LSUMNS B34270a & Muscle & AF353401 & AF353421 & AF353472 & AF353452 \\
\hline Streptopelia capicola & South Africa & LSUMNS B34271a & Muscle & AF279709 & AF353422 & AF279734 & AF279719 \\
\hline Streptopelia vinacea & Cent. Afr. Rep. & AMNH PRS-2168a & Muscle & AF353402 & AF353423 & AF353473 & AF353453 \\
\hline Streptopelia hypopyrrha & Cameroon & SDK 4 & Muscle & AF353403 & AF353424 & AF353474 & AF353454 \\
\hline Streptopelia turtur & Kazakhastan & UWBM DAB-236a & Muscle & AF353404 & AF353425 & AF353475 & AF353455 \\
\hline Streptopelia orientalis & Russia & UWBM 47282a & Muscle & AF353405 & AF353426 & AF353476 & AF353456 \\
\hline Streptopelia bitorquata & Captive & SDK 1 & Feather & AF353406 & AF353427 & AF353477 & AF353457 \\
\hline Streptopelia tranquebarica & Captive & SDK 2 & Feather & AF353407 & AF353428 & AF353478 & AF353458 \\
\hline Nesoenas (Streptopelia) mayeri & Captive & Tracy Aviary & Feather & AF353408 & AF353429 & AF353479 & AF353459 \\
\hline Streptopelia picturata & Madagascar & CC 1 & Feather & AF353409 & AF353430 & AF353480 & AF353460 \\
\hline Streptopelia chinensis & Philippines & FMNH DW-4712a & Muscle & AF182695 & AF353431 & AF353481 & AF182662 \\
\hline Streptopelia senegalensis & South Africa & LSUMNS B34209a & Muscle & AF279710 & AF353432 & AF279735 & AF279720 \\
\hline Columba liva & Utah & 423 & Muscle & AF182694 & AF353433 & AF279733 & AF182661 \\
\hline Columba rupestris & Mongolia & UWBM 59755ª & Muscle & AF353410 & AF353434 & AF353482 & AF353461 \\
\hline Columba guinea & South Africa & LSUMNS B34209a & Muscle & AF279708 & AF353435 & AF279732 & AF279718 \\
\hline Columba palumbus & Captive & Tracy Aviary & Muscle & AF353411 & AF353436 & AF353483 & AF353462 \\
\hline Columba arquatrix & South Africa & CC 2 & Feather & AF353412 & AF353437 & AF353484 & AF353463 \\
\hline Columba pulchrichollis & Captive & SDK 1 & Muscle & AF353413 & AF353438 & AF353485 & AF353464 \\
\hline Columba plumbea & Brazil & FMNH ATP86-136a & Muscle & AF182691 & AF251547 & AF279736 & AF182658 \\
\hline Columba subvinacea & Peru & FMNH SML-1045 a & Muscle & AF182692 & AF353439 & AF353486 & AF182659 \\
\hline Columba oenops & Peru & FMNH AJB-556 & Muscle & AF182690 & AF353440 & AF353487 & AF182657 \\
\hline Columba leucocephala & Florida & KUMNH B1798a & Muscle & AF182689 & AF353441 & AF353488 & AF182656 \\
\hline Columba speciosa & Mexico & KUMNH B2096a & Muscle & AF279711 & AF353442 & AF279737 & AF279721 \\
\hline Columba fasciata & Utah & DHC $1^{\mathrm{a}}$ & Muscle & AF353414 & AF353443 & AF353489 & AF353465 \\
\hline Macropygia mackinlayi & Solomon Islands & AMNH MKL-82a & Muscle & AF353415 & AF353444 & AF353490 & AF353466 \\
\hline Macropygia tenurirostris & Philippines & FMNH SEA-074a & Muscle & AF353416 & AF353445 & AF353491 & AF353467 \\
\hline Reinwardtoena browni & Captive & NMNH B4024a & Muscle & AF353417 & AF353446 & AF353492 & AF353468 \\
\hline Zenaida asiatica & Arizona & KPJ 5 & Muscle & AF251533 & AF251543 & AF279731 & AF258324 \\
\hline Zenaida macroura & Arizona & KPJ 5 & Muscle & AF251530 & AF251535 & AF353493 & AF258321 \\
\hline Geotrygon montana & Peru & KUMNH B995a & Muscle & AF182696 & AF353447 & AF279728 & AF182663 \\
\hline Leptotila rufaxilla & Peru & KUMNH B793a & Muscle & AF182698 & AF251546 & AF353494 & AF182665 \\
\hline Leptotila verreauxi & Texas & DHC $5^{\mathrm{a}}$ & Muscle & AF279705 & AF353448 & AF279725 & AF279715 \\
\hline
\end{tabular}


Table 2. Primers used in study.

\begin{tabular}{lll}
\hline \hline Gene & Primer name & \multicolumn{1}{c}{ Source } \\
\hline cyt $b$ & L14841 & Kocher et al. (1989) \\
& H4a & Harshman (1996) \\
& H15299 & Kocher et al. (1989) \\
L15517 & Johnson and Sorenson (1998) \\
ND2 & H5215 & Hackett (1996) \\
& H6313 & Johnson and Sorenson (1998) \\
COI & L5758 & Johnson and Sorenson (1998) \\
L6625 & Hafner et al. (1994) \\
FIB7 & H7005 & Hafner et al. (1994) \\
& FIB-BI7L & Prychitko and Moore (1997) \\
& FIB-BI7U & Prychitko and Moore (1997) \\
& FIB-DOVEF & Johnson and Clayton (2000a) \\
& FIB-DOVER & Johnson and Clayton (2000a) \\
\hline
\end{tabular}

test indicated no significant incongruence between any of the gene regions (see below), we also conducted several analyses with mitochondrial and nuclear genes separately. We did this because of the slow rate and lack of informative sites in the nuclear gene and because we wanted to identify what nodes were common to trees derived from independently sorting gene regions.

We conducted parsimony analyses with a range of transversion weighting schemes from 1:1 (unordered parsimony) to 20:1. For each weighting scheme, we used 50 random addition replicates with heuristic searches. For each analysis, we also performed 1,000 bootstrap replicates (Felsenstein 1985) to assess relative support for various branches in the phylogeny.

We used one of the combined unordered parsimony trees to estimate parameters for maximumlikelihood searches. We used likelihood ratio tests to estimate the best fit model that could not be rejected in favor of a simpler model (Huelsenbeck and Cran- dall 1997). Using the estimated model parameters, we conducted 50 heuristic maximum-likelihood searches with nearest neighbor interchange (NNI) branch swapping. We used bootstrapping (100 replicates with NNI branch swapping) to evaluate relative support for nodes in maximum-likelihood topologies.

\section{RESUlts}

Sequence variation.-Mitochondrial genes were similar in the fraction of sites that were variable and potentially phylogenetically informative, but ND2 showed the most variation, followed by cyt $b$, then COI (Table 4). FIB7 showed a much smaller fraction of variable and phylogenetically informative sites (Table 4). Within Streptopelia, mitochondrial sequence divergences ranged from 1.9 to $12.4 \%$. For those

TABLE 3. Samples sequenced for COI only.

\begin{tabular}{|c|c|c|c|c|}
\hline Species & Locality & Sample number & Tissue type & $\begin{array}{c}\text { GenBank } \\
\text { number }\end{array}$ \\
\hline Streptopelia decaocta & Netherlands & SDK 1 & Feather & AF353495 \\
\hline Streptopelia decaocto & Netherlands & SDK 2 & Feather & AF353496 \\
\hline Streptopelia roseogrisea & Cameroon & SDK 2 & Blood & AF353497 \\
\hline Streptopelia roseogrisea & Cameroon & SDK 3 & Feather & AF353498 \\
\hline Streptopelia decipiens & Cameroon & SDK 2 & Feather & AF353499 \\
\hline Streptopelia semitorquata & Cameroon & SDK 1 & Feather & AF353500 \\
\hline Streptopelia capicola & South Africa & LSUMNS B34205a & Muscle & AF353501 \\
\hline Streptopelia vinacea & Cameroon & SDK 1 & Feather & AF353502 \\
\hline Streptopelia hypopyrrha & Cameroon & SDK 2 & Feather & AF353503 \\
\hline Streptopelia turtur & Cameroon & SDK 1 & Feather & AF353504 \\
\hline Streptopelia turtur & Cameroon & SDK 2 & Feather & AF353505 \\
\hline Streptopelia orientalis & Captive & SDK 2 & Feather & AF353506 \\
\hline Streptopelia tarnquebarica & Captive & SDK 3 & Feather & AF353507 \\
\hline Streptopelia picturata & Captive & SDK 1 & Feather & AF353508 \\
\hline Streptopelia chinensis & Singapore & AMNH PRS-678a & Fuscle & AF353509 \\
\hline Streptopelia senegalensis & Cameroon & SDK 1 & Feather & AF353510 \\
\hline
\end{tabular}

a Indicates samples that have a corresponding museum skin voucher. 
TABLE 4. Variable and phylogenetically informative sites for each gene region.

\begin{tabular}{cccc}
\hline \hline Gene & $\begin{array}{c}\text { Number } \\
\text { of sites }\end{array}$ & $\begin{array}{c}\text { Percent } \\
\text { variable }\end{array}$ & $\begin{array}{c}\text { Percent } \\
\text { information }\end{array}$ \\
\hline cyt $b$ & 1070 & $39.0 \%$ & $33.1 \%$ \\
ND2 & 1067 & $48.7 \%$ & $39.8 \%$ \\
COI & 383 & $34.2 \%$ & $30.0 \%$ \\
FIB7 & 1150 & $19.6 \%$ & $7.9 \%$ \\
\hline
\end{tabular}

same comparisons, FIB7 showed much less divergence $(0.0$ to $1.4 \%)$. Plots of third position transitions against third position transversions for mitochondrial genes (Fig. 1) indicated considerable multiple substitution of third position transitions with an estimated transition: transversion ratio of approximately 10:1. Divergences of mitochondrial genes were similar, but comparisons of those divergences indicated that ND2 was less subject to multiple substitution than was cyt $b$ or COI, because plots of ND2 divergence against FIB7 or the other mitochondrial genes indicated continuing accumulation of substitutions at high divergences. The estimated transition:transversion ratio for FIB7 was approximately 1.5:1 (Fig. 3), with no evidence of multiple substitution of transitions compared to transversions. Plots of divergences for the mitochondrial genes against FIB7 divergence indicated a 5 to $10 \times$ higher rate of substitution in the mitochondrial genes (Fig. 4).

Several indels occurred in FIB7. One of those is a $166 \mathrm{bp}$ deletion shared by Streptopelia, $\mathrm{Ne}$ soenas, and Old World Columba. Other columbiform taxa do not show that deletion. Other indels in FIB7 ranged from 1 to $125 \mathrm{bp}$, but only two others were potentially phylogenetically informative (one uniting Streptopelia, Nesoenas, Old World Columba, and Macropygia the other uniting clade A of Streptopelia [Fig. 5]).

Within species, little sequence variation was evident. For the COI gene, within-species variation ranged from $0.0 \%$ (for 6 of 13 species with multiple samples) to $1.0 \%$ (for comparisons of Streptopelia semitorquata between South Africa and Cameroon). The low within-species variation for mitochondrial genes suggests that single species exemplars are suitable for species-level phylogenetic analysis, given that between-species divergences all exceeded $2.5 \%$.

Phylogeny.-Partition homogeneity tests comparing congruence among the three mitochon-

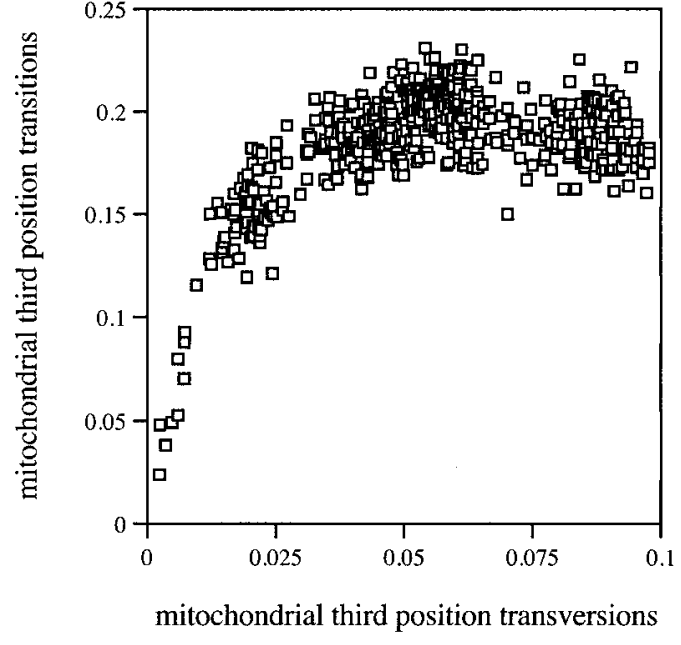

FIG. 1. Plot of pairwise percentage divergence for transitions against transversions for third positions of all mitochondrial genes combined.

drial genes indicate that those genes could be considered samples of the same underlying phylogeny $(P=0.44)$. Similarly, trees derived from FIB7 alone compared to trees for mitochondrial genes combined were not significantly incongruent $(P=1.0)$.

Unordered parsimony analysis of all three mitochondrial genes combined produced three equally parsimonious trees (not shown, but see Fig. 5 for reference). Those trees indicated that Streptopelia is not monophyletic. Nesoenas mayeri is the sister taxon to S. picturata with high bootstrap support. In addition, two groups of Streptopelia are sister to Old World Columba, but that result has only weak bootstrap support (49\%). One large group of Streptopelia is monophyletic (clade A) with strong support (100\%).

Transversion weighting of $2: 1$ to $5: 1$ produced identical tree topologies (one tree) that were completely resolved (not shown). Analysis of mitochondrial genes with those low transversion weights also produced a paraphyletic Streptopelia, both with respect to Nesoenas and with respect to Old World Columba. However, transversion weighting of 10:1 and higher produced a single tree showing monophyly of Streptopelia with respect to Old World Columba. Nesoenas was still sister to $S$. picturata, again with high bootstrap support.

Unordered parsimony analysis of the nuclear intron alone produced 32,020 trees (not shown). The high number of trees was not sim- 

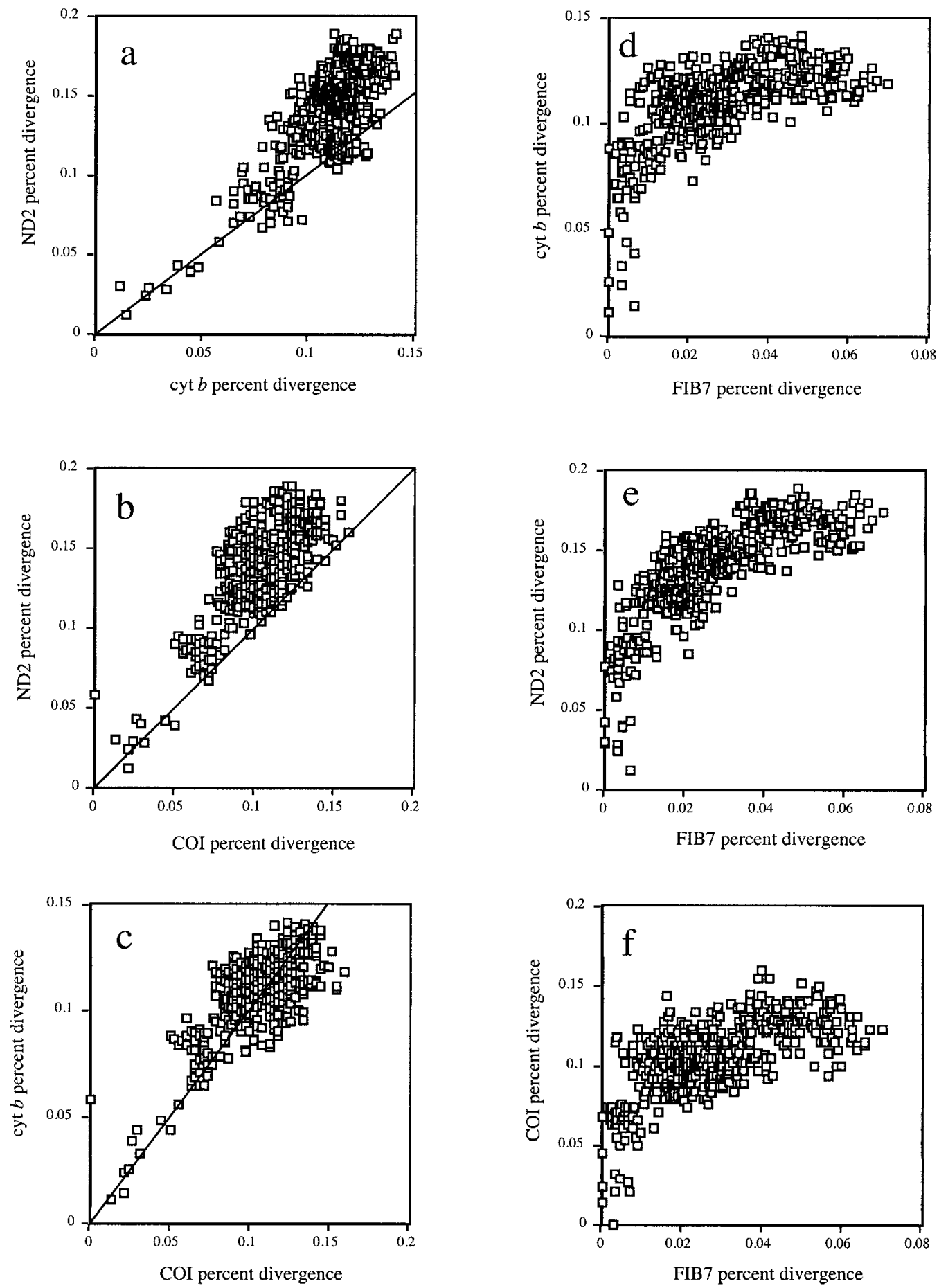

FIG. 2. Plot of pairwise percentage divergence for (A) ND2 versus cyt $b$, (B) ND2 versus COI, (C) cyt $b$ versus COI, (D) cyt $b$ versus FIB7, (E) ND2 versus FIB7, (F) COI versus FIB7. Lines for the mitochondrial gene plots $(\mathrm{A}-\mathrm{C})$ indicate expectation if rates are equal. 


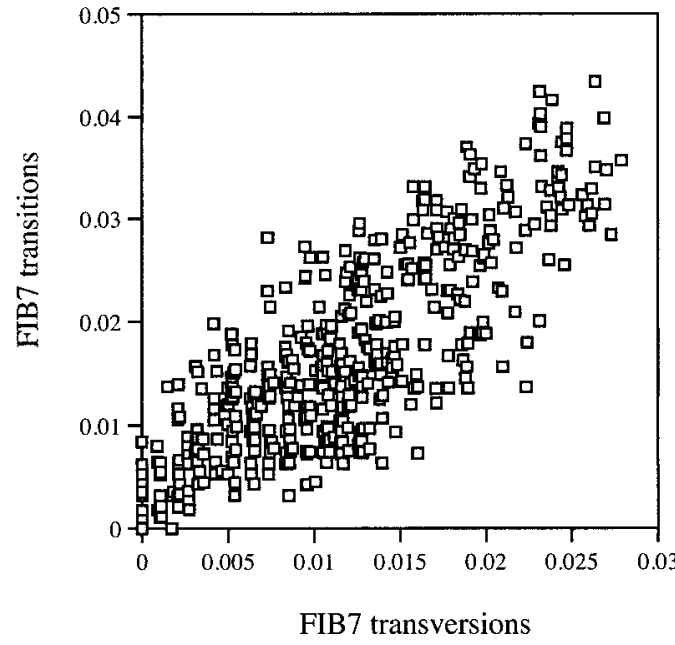

FIG. 3. Plot of pairwise percentage divergence for transitions against transversions for all positions of nuclear FIB7.

ply an artifact of incomplete sequences for Streptopelia bitorquata and S. tranquebarica. Exclusion of those sequences from phylogenetic analyses produced 4,236 trees, the consensus of which was identical to the consensus of trees with those taxa included. FIB7 trees did not resolve relationships among major Streptopelia lineages plus Old World Columba. However, New World Columba is placed outside Streptopelia and Old World Columba (bootstrap support $100 \%)$. Monophyly of both clades B and C of Streptopelia (see Fig. 5 for reference) was strongly supported in parsimony analyses of FIB7 alone, as was monophyly of Old World Columba.

Unordered parsimony analysis of combined gene regions (mitochondrial and nuclear) produced two trees (Fig. 5). Strict consensus of those trees, like unordered parsimony analysis of mitochondrial genes alone, does not recover a monophyletic Streptopelia with respect to Old World Columba. However, in most respects that tree is very similar to trees produced by separate analysis. Increasing transversion weighting of combined gene regions (in excess of 10: 1) produced trees with a monophyletic Streptopelia with respect to Old World Columba (not shown, see Fig. 6 for reference).

Likelihood ratio tests indicated that models incorporating unequal base frequencies, six substitution types, and rate heterogeneity were statistically better justified than simpler mod-

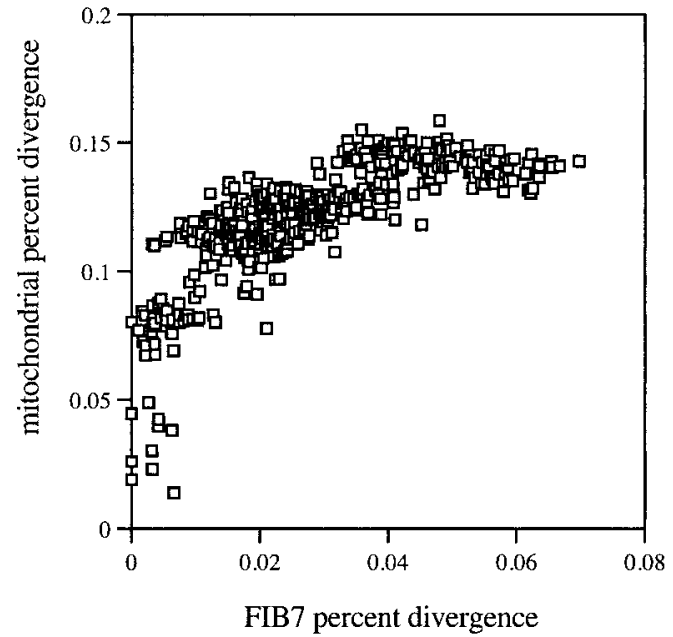

FIG. 4. Plot of overall percentage divergence for all mitochondrial genes combined against percentage divergence for nuclear FIB7.

els. Maximum-likelihood searches on mitochondrial genes alone produced a tree very similar to parsimony trees, and that tree indicated monophyly for Streptopelia with respect to Old World Columba. Likelihood analysis of the intron alone identifies monophyly for the three main clades of Streptopelia and Old World Columba, but does not resolve relationships among those groups. There is also little resolution within the large Streptopelia clade A. Maximum-likelihood trees for combined gene regions (Fig. 6) are well resolved and indicate monophyly for Streptopelia (inclusive of Nesoenas) with moderate support (bootstrap 64\%). The three main clades of Streptopelia identified by combined parsimony analysis are also recovered in that tree with strong support $(100 \%$ in each case), as is paraphyly of Columba $(100 \%$ bootstrap support for sister relationship between Old World Columba and Streptopelia). In fact, support for a sister relationship between New World Columba and Old World Columba + Streptopelia is relatively poor (51\%). Most other branches are identical to those recovered by unordered parsimony analysis (Fig. 5).

\section{DISCUSSION}

Phylogeny.-A phylogeny based on 2,530 bp of mitochondrial and 1,150 bp of nuclear DNA sequences is generally well resolved and well supported for the dove genus Streptopelia and 


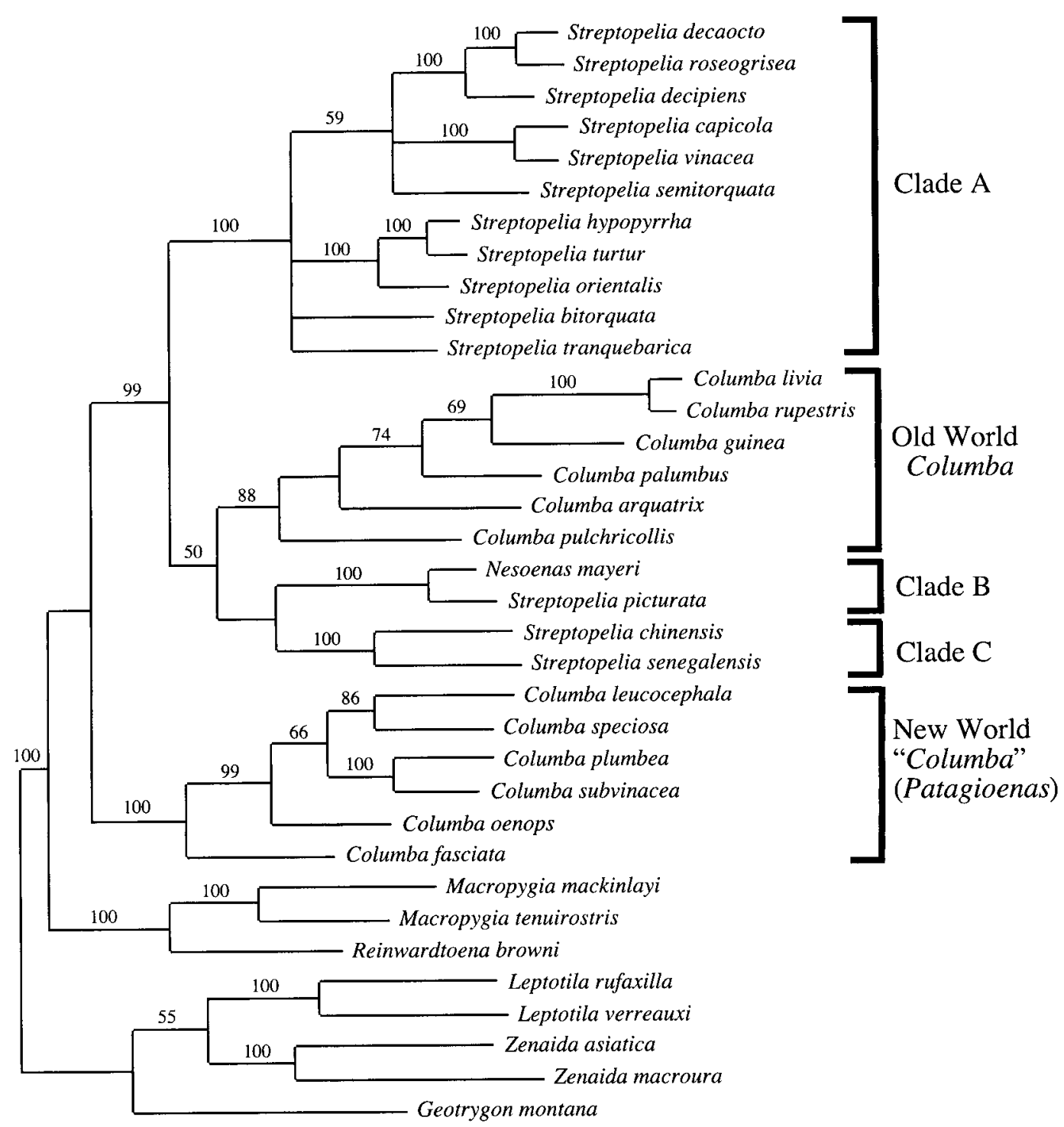

FIG. 5. Strict consensus of two trees (length $=4470, \mathrm{RC}=0.200$ ) from unordered parsimony analysis of combined mitochondrial (cyt $b, \mathrm{ND} 2, \mathrm{COI}$ ) and nuclear (FIB7) genes. Numbers above branches indicate bootstrap support from 1,000 full heuristic replicates. Unlabelled nodes received $<50 \%$ bootstrap support. Branch lengths are proportional to reconstructed changes using parsimony. Indicated groups are clades referred to in text.

outgroup taxa. However, even given the relatively large amount of DNA sequence data, some aspects of the tree are still weakly supported. Primary among those uncertainties is whether or not Streptopelia is monophyletic with respect to Old World Columba.

Despite the lower homoplasy present in the FIB7 sequences, mitochondrial genes provided better resolution for the phylogeny of Streptopelia. Mitochondrial genes have around a 5 to $10 \times$ higher substitution rate (Fig. 4), and thus variation can accumulate in mitochondrial DNA between closely related species. For several closely related species of Streptopelia, sequences of FIB7 were identical, preventing resolution of species level relationships. Importantly for this study, 


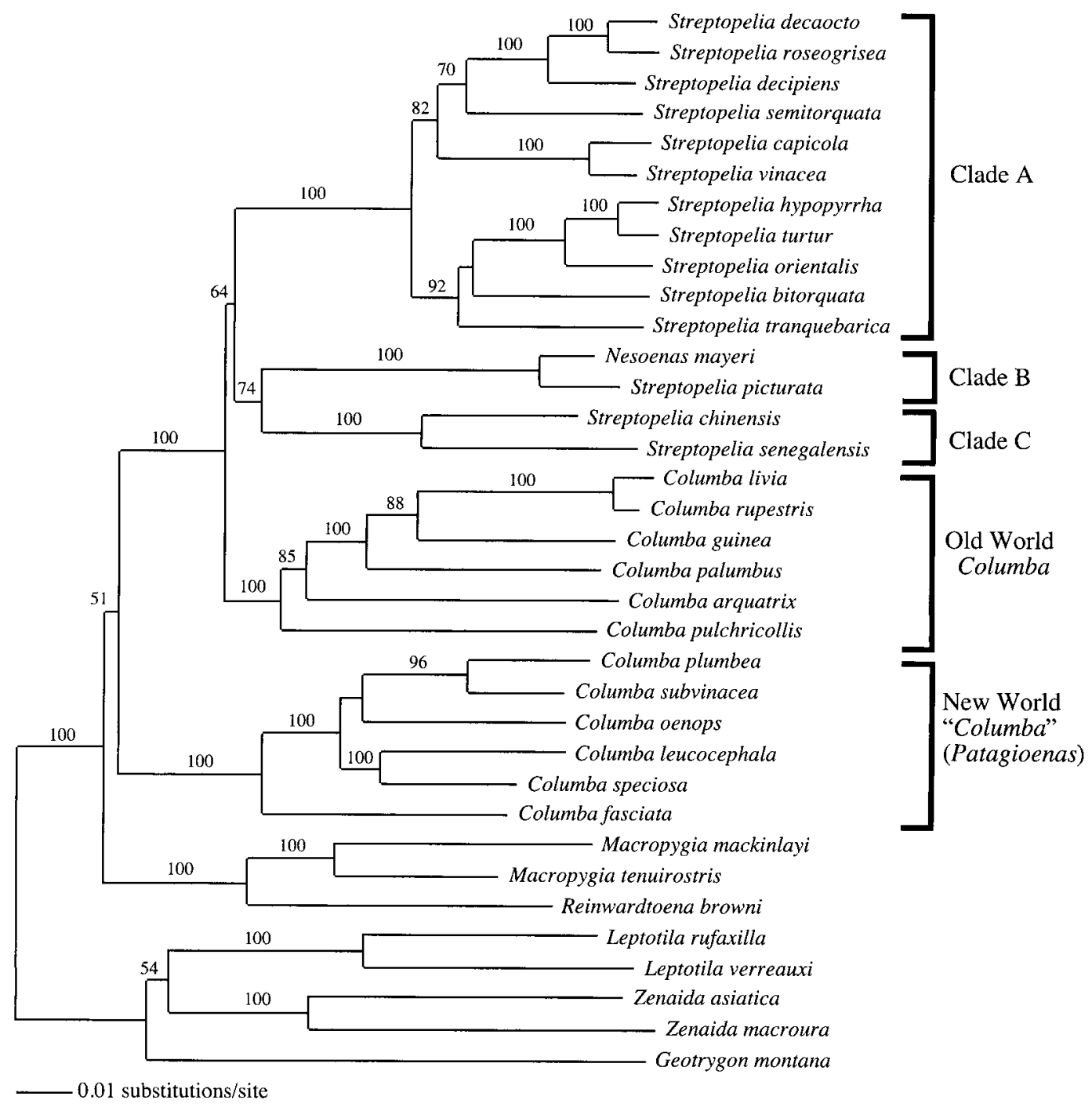

FIG. 6. Tree resulting from maximum likelihood searches using combined mitochondrial (cyt $b$, ND2, COI) and nuclear (FIB7) genes (ln likelihood $=-25,202$; model parameters: gamma shape parameter $=0.209$ with eight rate categories, transition matrix: $\mathrm{A}-\mathrm{C}=1.41, \mathrm{~A}-\mathrm{G}=17.96, \mathrm{~A}-\mathrm{T}=1.22, \mathrm{C}-\mathrm{G}=0.54, \mathrm{C}-\mathrm{T}=16.77$, $\mathrm{G}-\mathrm{T}=1.0$ ). Numbers above branches indicate bootstrap support from 100 heuristic search replicates. Unlabelled nodes received $<50 \%$ bootstrap support. Branch lengths are proportional to likelihood estimated branch lengths (scale indicated). Indicated groups are clades referred to in text.

trees based on FIB7 identified the same major clades that were identified by analyses of mitochondrial genes. In addition, there was no significant conflict between nuclear and mitochondrial data sets, suggesting that trees recovered in our analyses estimate the species' phylogeny rather than simply gene trees.

All analyses identify three major clades within Streptopelia (Figs. 5 and 6). Two of those groups involve only two species: S. chinensis + S. senegalensis (clade C) and S. picturata $+\mathrm{Ne}$ soenas (Streptopelia) mayeri (clade B). The other clade (A) includes all other species of Streptopelia. Monophyly of each of those clades is generally well supported, but relationships among those groups and Old World Columba is less clear. Analyses that take into account large transition:transversion biases (transversion-weight- 
ed parsimony and maximum likelihood) tend to recover monophyly for Streptopelia (inclusive of Nesoenas).

Phylogenetic relationships within Streptopelia do not correspond in a strong way to either Nowak's (1975) classification or Goodwin's (1983) hypothesized evolutionary relationships. However, similarities with both are evident. Nowak (1975) unites S. decipiens, capicola, vinacea, tranquebarica, semitorquata, roseogrisea, and decaocto into a subgenus. We find support for a similar clade (excluding tranquebarica). Goodwin (1983) outlines a similar group, but places tranquebarica outside of it and puts bitorquata close to decaocto. In our phylogenetic analyses, S. tranquebarica and $S$. bitorquata consistently fall at the base of a clade containing those two species plus $S$. orientalis, turtur, and hypopyrrha. Like many species of Streptopelia, tranquebarica and bitorquata possess a "ring-neck," unlike orientalis, turtur, and hypopyrrha that have a dark patch on the side of the neck. Our results suggest that the ring-neck (a dark bar running around the back of the neck) is the ancestral condition in group A of Streptopelia, having been lost in the ancestor of S. orientalis, turtur, and hypopyrrha. Species of Streptopelia outside group A tend to have spotting on the neck. The close relationship of S. chinensis and S. senegalensis was recognized by Goodwin (1983) and to some extent by Nowak (1975).

A novel finding of our study is the sister relationship between the Pink Pigeon (Nesoenas mayeri), which is endemic to Mauritius, and the Madagascan Turtle Dove (Streptopelia picturata), endemic to Madagascar. In most classifications, Nesoenas is united with species of Old World Columba whereas the Madagascan Turtle Dove is considered to be an aberrant Streptopelia. On the basis of the close relationship of those two species, we suggest that the common ancestor of the Pink Pigeon and the Madagascan Turtle Dove colonized Mauritius from Madagascar and subsequently speciated. Percentage divergence for mitochondrial genes between the Pink Pigeon and the Madagascan Turtle Dove is only $3.0 \%$. On the basis of mitochondrial molecular clock calibrations for birds (Klicka and Zink 1997), that represents a colonization time of $\sim 1.5$ Mya, much younger than the age of Mauritius (Proag 1995). Mitochondrial divergence between the Madagascan Turtle Dove and other species of Streptopelia ranges from 11.1 to $11.9 \%$, whereas the maximum mitochondrial divergences within clade A of Streptopelia range to $8.4 \%$.

Streptopelia vinacea and S. capicola are a pair of allopatric sister taxa of particular interest. Those taxa are distributed in sub-Saharan northern Africa and in southeastern Africa, respectively. Another pair of dove taxa with a similar distribution is Turtur abyssinicus and T. chalcospilos. Mitochondrial sequence divergence between S. vinacea and S. capicola is $2.5 \%$ and that between T. abyssinicus and T. chalcospilos is $1.7 \%$ (K. P. Johnson unpubl. data). Similarity in geographic distributions and genetic divergences suggests some common biogeographic factor underlying speciation between those species of Streptopelia and Turtur, perhaps $\sim 1$ Mya.

Taxonomic implications.-The Pink Pigeon, in the monotypic genus Nesoenas Salvadori 1893, is sister to Streptopelia picturata. That result is evidenced by two independent gene regions and receives strong support in all analyses. The sister relationship between Nesoenas mayeri (Mauritius) and S. picturata (Madagascar) is not surprising, given the geographic proximity of those two islands. In light of those results, we recommend transferring $N$. mayeri to the genus Streptopelia Bonaparte 1855.

Regarding the generic status of Streptopelia, our results do not conclusively demonstrate monophyly of Streptopelia. However, in analyses that take into account rate heterogeneity and transition biases, Streptopelia (as redefined to include Nesoenas mayeri) is monophyletic. On the basis of those results, we suggest retaining the name Streptopelia for all species currently in the genus. An alternative would be to recognize the three main clades $(\mathrm{A}-\mathrm{C})$ as separate genera, but we feel a more conservative approach, minimizing name changes, is prudent.

All of our analyses indicated that Old World Columba species are sister to, or imbedded within, Streptopelia. That phylogenetic position results in paraphyly for Columba. Our current study confirms preliminary results of Johnson and Clayton (2000a), which also indicated that relationship. Because Columba for Old World species has priority, we recommend transferring all species of New World Columba into the genus Patagioenas (as partially suggested by Johnston 1962). Johnston (1962) suggested that the Band-tailed Pigeon (Columba fasciata) is a 
close relative of Old World Columba; however, our results strongly supported monophyly of New World "Columba," inclusive of fasciata. Further analysis is needed to determine if all New and Old World "Columba" species cluster by biogeographic distribution, but we suspect that will be the case.

Vocal evolution.-Streptopelia vocalizations have been studied extensively (Lade and Thorpe 1964, Gaunt et al. 1982, Cheng 1992, Ballintijn and ten Cate 1997, Slabbekoorn and ten Cate 1998, Slabbekoorn et al. 1999), making that genus an important group for comparative studies of vocalizations. Slabbekoorn et al. (1999) compared acoustic similarity of Streptopelia perchcoos with Goodwin's ideas on taxonomy (1983). They concluded that, at the species level, there is little congruence between similarity in perchcoos and phylogenetic relatedness, suggesting that environmental or social factors promote the relatively rapid diversification of perch-coo vocalizations. Although a formal reanalysis is beyond the scope of this paper, an informal comparison of acoustic similarity in relation to our phylogeny does not contradict Slabbekoorn et al.'s (1999) conclusions.

The close phylogenetic relationship between Streptopelia picturata and S. "Nesoenas" mayeri is somewhat surprising on the basis of morphological characters, but is supported by vocal characteristics. First, the relationship in general between Streptopelia and "Nesoenas" is supported by similarities in the Excitement Cry (Baptista 1997). More dramatically, the perchcoos of S. picturata and S. mayeri are very similar (Fig. 7), unlike comparisons of many other sister pairs of Streptopelia. Two other sister species pairs also show some similarity in vocalizations as compared to other Streptopelia species: vinacea-capicola and turtur-hypopyrrha. Although those species pairs group together in a similarity analysis, they can be separated unambiguously on the basis of acoustic parameters (Slabbekoorn et al. 1999). Thus perch-coos of other sister species pairs show structural acoustic differences (e.g. Fig. 7), which is not the case between $S$. mayeri and picturata. The latter instead show considerable divergence in morphological features, including a lack of any neck pattern and a reddish bill in $S$. mayeri. Those features, among others, are the reasons that $S$. mayeri has often been placed in a monotypic genus. In contrast, most other species of

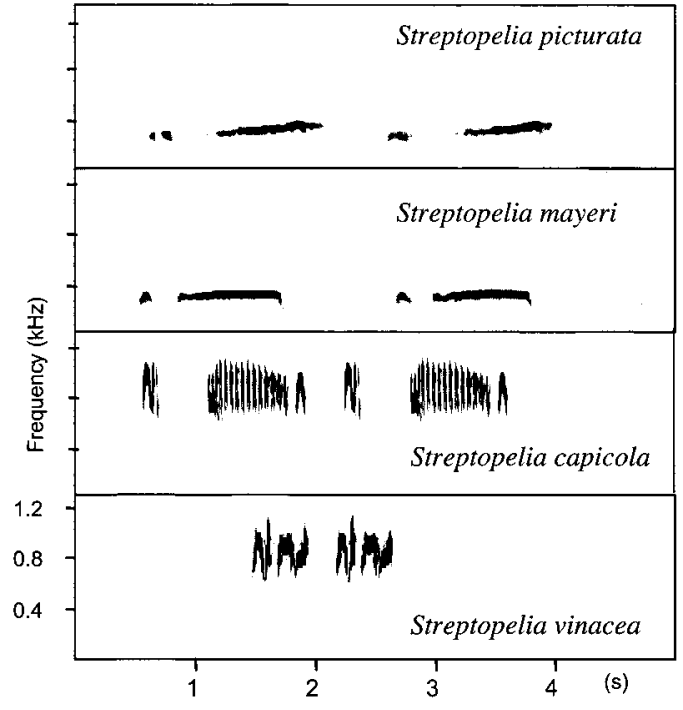

FIG. 7. Sonograms of selected Streptopelia perchcoos. Note the similarity between $S$. picturata and $S$. mayeri. Sonograms of $S$. capicola and $S$. vinacea represent two sister species of smaller genetic divergence, but greater divergence in perch-coo vocalizations.

Streptopelia are quite homogeneous in morphological characteristics. In fact, often the most reliable way to discriminate species in the field is by their distinctive perch-coos. Generally speaking, vocalizations in Streptopelia seem to be evolutionarily labile compared to morphological characteristics.

Two hypotheses explain why Streptopelia picturata and S. mayeri show the greatest degree of vocal similarity within Streptopelia (Slabbekoorn et al. 1999). First, selection may favor divergence between vocalizations of sympatric species, because of a need to use a signal that can be distinguished from that of closely related species (Nelson and Marler 1990). Unlike other Streptopelia species, S. picturata and S. mayeri are allopatric with all other congeners, perhaps reducing need for divergence in signal structure. Second, environment and habitat often play important roles in evolution of avian signals (Morton 1975, Wiley and Richards 1978, Marchetti 1993, Endler and Théry 1996, Johnson 2000, Johnson and Lanyon 2000). Both S. picturata and $S$. mayeri predominantly inhabit densely forested habitats through which their low-pitched vocalizations should propagate further than high-pitched vocalizations (Morton 1975, Wiley and Richards 1978, Ryan and 
Brenowitz 1985, McCracken and Sheldon 1997). Further evidence for potential stabilizing selection on the perch-coos of those two species comes from examination of the relationship between body size and sound frequency. In New World pigeons, a negative correlation exists between body weight and perch-coo frequency (Tubaro and Mahler 1998). That relationship is not apparent in the perch-coos of S. picturata and $S$. mayeri, because $S$. mayeri is nearly twice as heavy as $S$. picturata, yet sound frequencies of the perch-coos are very similar (Fig. 7). One or both of these factors may have caused vocalizations of those two species to remain relatively unchanged since speciation.

One other unexpected phylogenetic relationship is also supported by careful examination of vocalizations. Exclusion of Streptopelia bitorquata and $S$. tranquebarica, despite similarity in plumage characteristics, from the group of typical ring-necked doves (decaocto through vinacea clade) is somewhat surprising. The Excitement or Flight Call is a conspicuous characteristic for the true ring-necked species (as defined above). That display, in the same context, is absent in S. bitorquata and S. tranquebarica. Absence of that display is shared with S. hypoppyrha, turtur, and orientalis, the close relatives of bitorquata and tranquebarica. Likewise the bow-coo of those two species is very similar to that of $S$. hypoppyrha, turtur, and orientalis (S. de Kort unpubl. data). In sum, despite the overall diversity and rapid evolution of vocalizations in Streptopelia, some behaviors reflect phylogenetic relationships.

\section{ACKNOWLEDGMENTS}

We are grateful to the following individuals and institutions (and curators thereof) who were instrumental in providing samples: American Museum of Natural History, Field Museum of Natural History, University of Kansas Museum of Natural History, Louisiana State University Museum of Natural Science, U.S. National Museum, University of Washington Burke Museum, the Tracy Aviary, and Charlie Collins. The following individuals and organizations provided field assistance in collecting specimens: Sarah Al-Tamimi, Jason Weckstein, Rob Moyle, Nigella Hilgarth, Tony Jones, Aldolfo Navarro, A. Townsend Peterson, Mark Robbins, Moussa Barka, Imar Moussa, Wil Silkens, Arizona Fish and Game, Texas Parks and Wildlife, and the U.S. Fish and Wildlife Service. M. Griekspoor provided sound recordings. Dave Enstrom, Larry Page, Fred Sheldon, and two anony- mous reviewers provided helpful comments on this manuscript. We thank the DNA Sequencing Facility at the University of Utah, supported in part by National Cancer Institute grant \#5p30CA42014. This work was supported by NSF-CAREER award DEB9703003 to D.H.C.

\section{Literature Cited}

Ballintijn, M. R., And C. TEn Cate. 1997. Sex differences in vocalizations and syrinx of the Collared Dove (Streptopelia decaocto). Auk 114:22-39.

BAptistA, L. 1997. Family Columbidae (Pigeons and Doves). Pages 60-243 in Handbook of the Birds of the World, vol. 4. Sandgrouse to Cuckoos (J. del Hoyo, A. Elliott, and J. Sargatal, Eds.). Lynx Edicions, Barcelona, Spain.

BijlsmA, R. G. 1988. Population growth in the Collared Dove Streptopelia decaocto in the Netherlands. Limosa 61:41-42.

Cheng, M. F. 1986. Female cooing promotes oviarian development in Ring Doves (Streptopelia risoria). Physiology and Behavior 37:371-374.

Cheng, M. F. 1992. For whom does the female dove coo? A case for the role of vocal self-stimulation. Animal Behaviour 43:1035-1044.

Cheng, M. F., M. Porter, And G. Ball. 1981. Do Ring Doves copulate more than necessary for fertilization? Physiology and Behavior 27:659662.

ENDLER, J. A., AND M. THÉRY. 1996. Interacting effects of lek placement, display behavior, ambient light, and color patterns in three Neotropical forest-dwelling birds. American Naturalist 148: 421-452.

Farris, J. S., M. Kallersjo, A. G. Kluge, and C. Bult. 1994. Testing significance of congruence. Cladistics 10:315-320.

Farris, J. S., M. Kallersjo, A. G. Kluge, and C. Bult. 1995. Constructing a significance test for incongruence. Systematic Biology 44:570-572.

Felsenstein, J. 1985. Confidence limits on phylogenies: An approach using the bootstrap. Evolution 39:783-791.

GAunt, A. S., S. L. L. Gaunt, AND R. M. CASEy. 1982. Syringeal mechanisms reassessed: Evidence from Streptopelia. Auk 99:474-494.

Georgiou, G. C., P. J. Sharp, and R. W. Lea. 1995. (14C) 2-Deoxyglucose uptake in the brain of the Ring Dove (Streptopelia risoria). II. Differential uptake at the onset of incubation. Brain Research 700:137-141.

Goodwin, D. 1983. Pigeons and Doves of the World, 3rd ed. Cornell University Press, Ithaca, New York.

HACKeTt, S. J. 1996. Molecular phylogenetics and biogeography of tanagers in the genus Ramphocelus (Aves). Molecular Phylogenetics and Evolution 5:368-382. 
Hafner, M. S., P. D. Sudman, F. X. Villablanca, T. A. Spradling, J. W. Demastes, and S. A. NadLER. 1994. Disparate rates of molecular evolution in cospeciating hosts and parasites. Science 365: 1087-1090.

HARShMAN, J. 1996. Phylogeny, evolutionary rates, and ducks. Ph.D. dissertation. University of Chicago, Chicago.

Hengeveld, R. 1993. What to do about the North American invasion by the Collared Dove? Journal of Field Ornithology 64:477-489.

Hengeveld, R., AND F. VAN DeN Bosch. 1991. The expansion velocity of the Collared Dove Streptopelia decaocto population in Europe. Ardea 79: $67-72$.

Huelsenbeck, J. P., AND K. A. Crandall. 1997. Phylogeny estimation and hypothesis testing using maximum likelihood. Annual Review of Ecology and Systematics 28:437-466.

JANIK, D. S., AND J. D. BUNTIN. 1985. Behavioral and physiological effects of prolactin in incubating doves (Streptopelia risoria). Journal of Endocrinology 105:201-210.

JoHnson, K. P. 2000. The evolution of courtship display repertoire size in the dabbling ducks (Anatini). Journal of Evolutionary Biology 13:636644.

JOHNSON, K. P., AND D. H. ClaytON. 2000a. Nuclear and mitochondrial genes contain similar phylogenetic signal for pigeons and doves (Aves: Columbiformes). Molecular Phylogenetics and Evolution 14:141-151.

Johnson, K. P., AND D. H. Clayton. 2000b. A molecular phylogeny of the dove genus Zenaida: Mitochondrial and nuclear DNA sequences. Condor 102:864-870.

JOHNSON, K. P., AND S. M. LANYON. 1999. Molecular systematics of the grackles and allies, and the effect of additional sequence (cyt $b$ and ND2). Auk 116:759-768

JOHNSON, K. P., AND S. M. LANYON. 2000. Evolutionary change in color patches of blackbirds are associated with marsh nesting. Behavioral Ecology 11:515-519.

JOHNSON, K. P., AND M. D. SORENSON. 1998. Comparing molecular evolution in two mitochondrial protein coding genes (cytochrome $b$ and ND2) in the dabbling ducks (Tribe: Anatini). Molecular Phylogenetics and Evolution 10:82-94.

JoHNSTON, R. F. 1962. The taxonomy of pigeons. Condor 64:69-74.

KASPAREK, M. 1996. Dispersal and range extension of the Collared Dove (Streptopelia decaocto) in Europe. Journal für Ornithologie 137:1-33.

KLICKA, J. T., AND R. M. ZINK. 1997. The importance of recent ice ages in speciation: A failed paradigm. Science 277:1666-1669.

Kocher, T. D., W. K. Thomas, A. Meyer, S. V. EDWARDS, S. PÄÄBo, F. X. Villablanca, AND A. C.
WiLSON. 1989. Dynamics of mitochondrial DNA evolution in animals: Amplification and sequencing with conserved primers. Proceedings of the National Academy of Sciences USA 86: 6196-6200.

LADE, B. I., AND W. H. THORPE. 1964. Dove songs are innately coded patterns of specific behaviour. Nature 202:366-368.

Lea, R. W., G. C. Georgiou, Q. Li, R. J. Sterling, AND P. J. SHARP. 1995. (14C) 2-Deoxyglucose uptake in the brain of the Ring Dove (Streptopelia risoria). I. Prolactin-induced uptake. Brain Research 700:129-136.

MARChetTI, K. 1993. Dark habitats and bright birds illustrate the role of environment in species divergence. Nature 362:149-152.

McCracken, K. G., AND F. H. SHeldon. 1997. Avian vocalizations and phylogenetic signal. Proceedings of the National Academy of Science USA 94: 3833-3836.

MORTON, E. S. 1975. Ecological sources of selection on avian sounds. American Naturalist 108:1734 .

Nelson, D. A., ANd P. Marler. 1990. The perception of bird song and an ecological concept of signal space. Pages 443-478 in Comparative Perception, vol. 2: Complex Signals (W. C. Stebbins and M. A. Berkeley, Eds.). John Wiley and Sons, New York.

NowAK, E. 1975. Zur Systematik der Gattung Streptopelia (Columbiformes, Aves). Bonner Zoologische Beitraege 26:135-154.

ProAG, V. 1995. The Geology and Water Resources of Mauritius. Mahatma Gandhi Institute, Moka, Mauritius.

PrYchitKo, T. M., AND W. S. MoORE. 1997. The utility of DNA sequences from an intron from the $\beta$-fibrinogen gene in phylogenetic analysis of woodpeckers (Aves: Picidae). Molecular Phylogenetics and Evolution 8:193-204.

RAMOS, C., AND R. SILVER. 1992. Gonadal hormones determine sex differences in timing of incubation by doves. Hormones and Behavior 26:586601.

RYAN, M. J., AND E. A. BRENOWITZ. 1985. The role of body size, phylogeny, and ambient noise in the evolution of bird song. American Naturalist 126: 87-100.

Slabbekoorn, H., S. de Kort, and C. Ten CAte. 1999. Comparative analysis of perch-coo vocalizations in Streptopelia doves. Auk 116:737-748.

SlabbeKoorn, H., AND C. TEN CATE. 1998. Multiple parameters in the territorial coo of the Collared Dove: Interactions and meaning. Behaviour 135: 879-895.

SORENSON, M. D., AND T. W. QUINN. 1998. Numts: A challenge for avian systematics and population biology. Auk 115:214-221. 
Sturmbauer, C., And A. Meyer. 1992. Genetic divergence, speciation, and morphological stasis in the lineage of African cichlid fishes. Nature 358:578-581.

SWOFFORD, D. L. 2000. PAUP*: Phylogenetic Analysis Using Parsimony, version 4.0. Sinauer, Sunderland, Massachusetts.

ten Cate, C., R. W. Lea, M. R. Ballintijn, And P. J. SHARP. 1993. Brood size affects behavior, interclutch interval, LH levels, and weight in Ring Dove (Streptopelia risoria) breeding pairs. Hormones and Behavior 27:539-550.

Tubaro, P. L., AND B. Mahler. 1998. Acoustic frequencies and body mass in the New World doves. Condor 100:54-61.
Walker, L. E., J. M. Walker, J. W. Palca, And R. J. BERGER. 1983. A continuum of sleep and shallow torpor in fasting doves (Streptopelia risoria). Science 221:194-195.

Wiley, R. H., AND D. G. Richards. 1978. Physical constraints on acoustic communication in the atmosphere: Implications for the evolution of animal vocalizations. Behavioral Ecology and Sociobiology 3:69-94.

ZeNONE, P. G., M. E. SiMS, AND C. J. ERICKSON. 1979. Male Ring Dove (Streptopelia risoria) behavior and the defense of genetic paternity. American Naturalist 114:615-626.

Associate Editor: F. Sheldon 